\title{
An Investigation of SILAR Grown Cobalt Selenide Thin Films
}

Ho Soonmin

Faculty of Health \& Life Sciences, INTI International University, Putra Nilai, 71800, Negeri Sembilan, Malaysia. Email: soonmin.ho@newinti.edu.my

DOI: http://doi.org/10.38177/AJBSR.2022.4101

Copyright: () 2022 Ho Soonmin. This is an open access article distributed under the terms of the Creative Commons Attribution License, which permits unrestricted use, distribution, and reproduction in any medium, provided the original author and source are credited.

Nowadays, several deposition techniques have been used to produce thin film materials. The obtained films were characterized by using different tools. These semiconductor materials could be employed in solar cell, laser devices and opto-electronic devices. The main objective of this work is to produce cobalt selenide thin films through successive ionic layer adsorption and reaction method. Advantages of this method include simple procedures, inexpensive equipment, it does not need expensive vacuum system and high quality substrate. During the deposition process, the films were deposited onto soda lime glass under various anionic bath immersion times. The properties of the films were studied for the first time via field emission scanning electron microscopy (FESEM) and UV-visible spectrophotometer. Based on the FESEM analysis, uniform morphology could be observed for the sample produced for 30 seconds (anionic immersion time). The band gap was about $2.6 \mathrm{eV}$ and the optical transmission increased in the visible region could be detected for these samples.

Keywords: Thin films, Semiconductor, Band gap, Cobalt selenide, SILAR method, Solar energy.

\section{Introduction}

The thin film deposition is defined as technique of depositing thin film coatings onto substrate [1-3]. Researchers described that several deposition methods achieved the requirements of highly oriented thin film growth. These deposition methods such as aerosol assisted chemical vapour deposition [4], SILAR method, pulsed laser deposition [5], solvo thermal technique [6], electron beam evaporation technique [7], molecular beam epitaxy method [8], radio frequency sputtering technique [9], chemical bath deposition method [10-12], atomic layer deposition technique [13], spray pyrolysis method [14], and electro deposition method [15-17]. The obtained films could be employed in several applications including opto-electronic [18, 19], solid state and medical devices [20]. Because of these films indicated very unique properties including high dielectric constant, good absorption coefficient [21-23], excellent refractive index, and wide band gap [24-26].

The optical, electrical, morphological, compositional and structural techniques were becoming important tools in materials research. Several tools such as Scanning probe microscopy [27], X-ray photoelectron spectroscopy [28], X-ray diffractometry, Transmission electron microscopy [29], Fourier transform infrared spectroscopy [30], Atomic force microscopy, reflection high-energy electron diffraction [31], Field emission scanning electron microscopy [32], and Raman spectroscopy [33] were used for the characterization purposes.

The successive ionic layer adsorption and reaction (SILAR) technique has been employed for the production of metal sulfide, metal telluride and metal selenide films. During the formation of thin films, the cleaned glass substrate immerses into beaker contained different solutions (cationic and anionic precursor solution [34]), to ensure that these ions could be adsorbed successfully onto the surface of substrate. Then, distilled water was used to clean the substrate to remove undesired materials onto the surface of substrate [35]. Cobalt could be observed in the d-block elements in the Period Table. Cobalt showed the atomic number "27, and could be observed in 
erythrite, cobaltite and skutterudite [Table 1]. Selenium is semiconductor, and produced some allotropes that interconvert with temperature changes. Selenium is rare, it is located in Group 16 with chemical symbol "Se" and atomic number "34" [Table 1].

Table 1. The facts about cobalt and selenium

\begin{tabular}{|c|c|c|}
\hline Name & Cobalt & Selenium \\
\hline Atomic number & 27 & 34 \\
\hline Chemical symbol & Co & Se \\
\hline Sources & erythrite, cobaltite and skutterudite & soil, water and some foods \\
\hline
\end{tabular}

\section{Objectives of the Study}

In this work, synthesis of cobalt selenide thin films by using SILAR deposition method onto soda lime glass under various anionic bath immersion times. The main aim is to study the influence of various anionic bath immersion times (20 and 30 seconds) on the properties of the obtained films. Characterization of the films could be carried out through field emission scanning electron microscopy (study the morphology) and UV-visible spectroscopy (investigate the optical properties), respectively.

\section{Materials and Methods}

\subsection{Preparation of thin films}

In this work, several chemicals (cobalt (II) chloride hexahydrate, and sodium selenite) were employed for the production of cobalt selenide thin films (without further purification). The soda lime glass was used as substrate during the formation of films. During the experiment, acetone and de-ionized water were used to clean the substrate and remove dirty particles on the soda lime glass. The influence of various anionic bath immersion times on the properties of the films was studied for the first time. During the deposition process (at room temperature, 30 deposition cycles), the cleaned and washed soda lime glass slide was immersed in the beaker contained $0.2 \mathrm{M}$ of cobalt (II) chloride hexahydrate solution for 20 seconds. Then, washed with de-ionized water (5 seconds). Following that, the substrate was dipped into another beaker contained $0.2 \mathrm{M}$ of sodium selenite solution (20 and 30 seconds). Finally, washed with de-ionized water $(5 \mathrm{sec})$ to remove un-wanted materials from surface of substrate.

\subsection{Characterization of thin fims}

The morphology of obtained films was studied by using field emission scanning electron microscope (FEI, Nova Nanosem 230). The Perkin Elmer UV/Vis Lambda 35 Spectrophotometer was utilized for the characterization of the films such as optical properties and band gap energy.

\section{Results and Discussions}

The preparation of cobalt selenide thin films has been described by many research groups using various deposition methods. These deposition methods could be divided into two broad groups, namely physical deposition method 
and chemical deposition technique. Each of these deposition methods showed advantage and limitation as well [Table 2]. The selection of the deposition method chiefly depended on the applications, properties of films, and cost of manufacturing.

Table 2. Summary of the advantages and limitations for different deposition methods

\begin{tabular}{|l|l|}
\hline Advantages of SILAR method & Limitations of other deposition methods \\
\hline $\begin{array}{l}\text { large area deposition at low } \\
\text { temperature [36] }\end{array}$ & $\begin{array}{l}\text { Low deposition rate could be observed by using CVD } \\
\text { method [40] }\end{array}$ \\
\hline $\begin{array}{l}\text { starting materials used are } \\
\text { commonly available [37] }\end{array}$ & $\begin{array}{l}\text { Very difficult to control composition of samples by using } \\
\text { sputtering method [41] }\end{array}$ \\
\hline can control the film thickness & $\begin{array}{l}\text { It requires substrate heating by using thermal } \\
\text { co-evaporation method [42] }\end{array}$ \\
\hline Simple experimental set up [38] & $\begin{array}{l}\text { It requires accurate control of deposition rate and } \\
\text { temperature by using thermal co-evaporation method [43] }\end{array}$ \\
\hline $\begin{array}{l}\text { low cost deposition method [39] } \\
\text { Good growth rate of thin films } \\
\text { could be observed }\end{array}$ & $\begin{array}{l}\text { Long thickness uniformity on samples by using electro } \\
\text { deposition method [44] }\end{array}$ \\
\hline
\end{tabular}

Fig.1 indicated the field emission scanning electron microscopy (FESEM) images of the cobalt selenide thin films produced by using SILAR deposition technique with various anionic bath immersion times. The FESEM analysis confirmed that uniform grain size (about $1 \mu \mathrm{m}$ to $2 \mu \mathrm{m}$ ) and covered the entire surface of substrate for the thin films prepared at higher value of anionic immersion time (30 seconds).

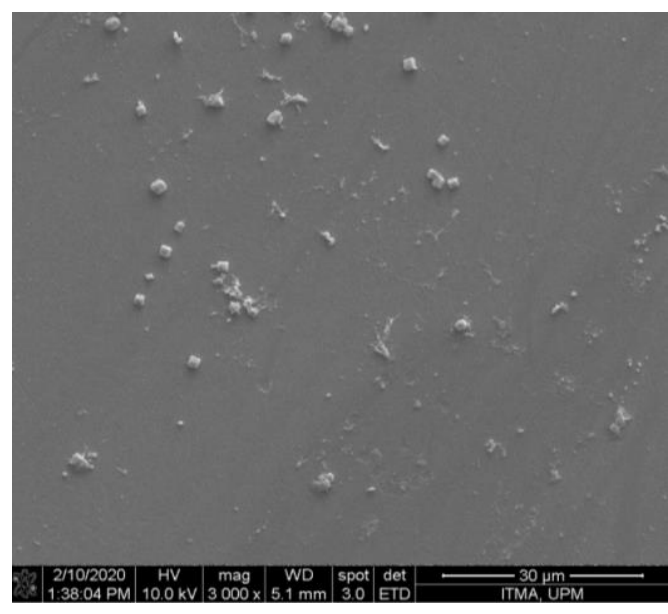

(a)

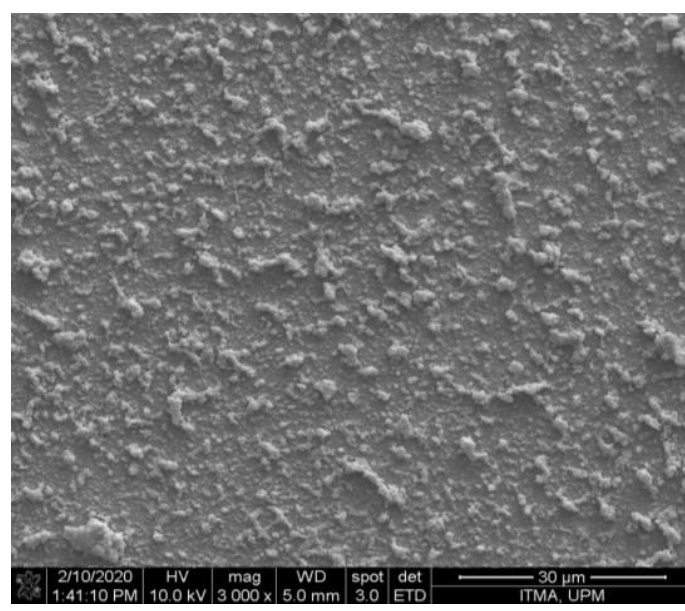

(b)

Fig.1. FESEM images of cobalt selenide thin films prepared at various anionic bath immersion times

(a) 20 seconds (b) 30 seconds 
However, smaller grain size $(0.5 \mu \mathrm{m}$ to $0.8 \mu \mathrm{m})$ and non-uniform surface morphology could be observed for the sample prepared at the lower anionic immersion time (20 seconds). Many researchers reported that more and more big particles appeared as the deposition time was increased. Further, they explain that the growth of particles (same deposition temperature) strongly depended onto longer deposition time [46-50].

The UV-visible spectroscopy is considered as very important tool to study the absorbance of the films at specific wavelength based on the electronic transition in molecules [51-54]. Fig.2 indicated the optical properties of thin films, determined by using UV-visible spectrometer (regions of 400 to $900 \mathrm{~nm}$ ). The obtained films exhibited optical transmission increased in the visible region. Egwunyenga and co-workers reported that the transmittance of CoSe films increase as wavelength increases [55]. On the other hand, the Stern equation was employed to calculate the band gap of the thin films.

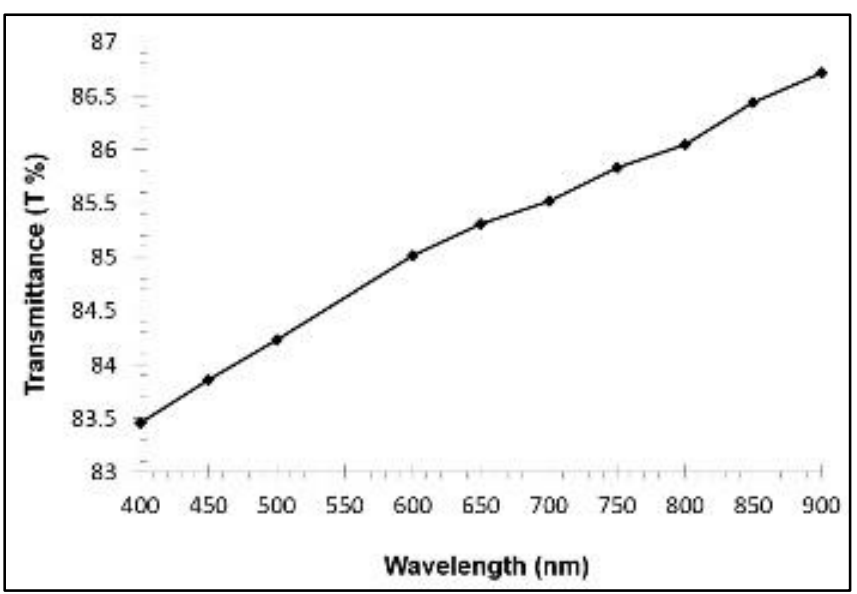

Fig.2. Transmission spectrum for cobalt selenide thin films prepared at the anionic immersion time (30 seconds) $A=\frac{\left[k\left(h v-E_{g}\right)^{n / 2}\right.}{h v}[$ Equation 1]

Some symbols in this equation such as $v, h$ and $k$ could be defined as frequency, Planck's constant, and constant value, respectively. The $n$ value could be highlighted as 1 (direct gap material) or 4 (indirect gap material) in this work. In the analysis part, the band gap value was determined based on the extrapolating the linear line portion as indicated in fig. 3 . The band gap of these samples about $2.6 \mathrm{eV}$.

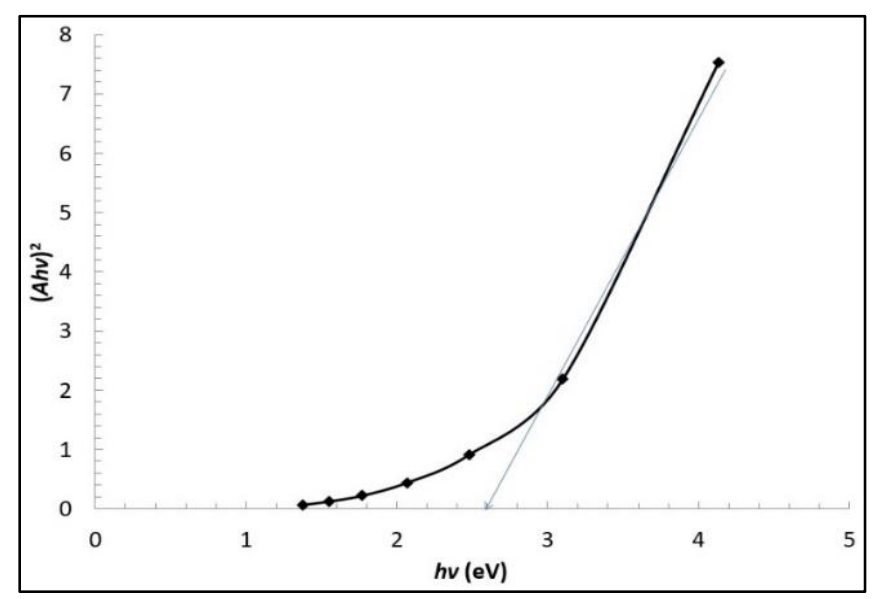

Fig.3. Curve $(A h v)^{2}$ against $(h v)$ for cobalt selenide thin films prepared at the anionic immersion time (30 seconds) 
According to the literature review, many research groups have highlighted the band gap of cobalt selenide thin films in their works. The optical properties indicated that the band gap values are in the range of $1.7 \mathrm{eV}$ to $3.6 \mathrm{eV}$ for the films prepared via chemical bath deposition method [56,57]. Band gap of $1.7 \mathrm{eV}$, and $1.53 \mathrm{eV}$ could be observed for the films produced using mechano chemical method [58], magnetron sputtering [59] and electro deposition technique [60,61], respectively.

\section{Conclusion}

The nanostructured cobalt selenide thin films have been produced onto soda lime glass slide by using successive ionic layer adsorption and reaction method under various anionic bath immersion times. The FESEM analysis showed that uniform grain size and covered the entire surface of substrate for the thin films prepared at higher value of anionic immersion time (30 seconds). These films displayed optical transmission increased in the visible region and indicated band gap about $2.6 \mathrm{eV}$.

\section{Declarations}

\section{Source of Funding}

This this research work was supported by INTI International University under INTI Internal Research Grant INTI -CAE-01-01-2018.

\section{Competing Interests Statement}

The author declares no competing financial, professional and personal interests.

\section{Consent for publication}

Author declares that he consented for the publication of this research work.

\section{Availability of data and material}

Author is willing to share data and material according to the relevant needs.

\section{References}

[1] G. Hasan, M. Hazhir, M. Rostam, Effects of deposition time on structural and optical properties of ZnS and $\mathrm{ZnS} / \mathrm{Au}$ thin films grown by thermal evaporation, Physica B: Condensed Matter, 627, (2022), https://doi.org/10.1016/j.physb.2021.413616.

[2] Teoman, H. Kavak, Single step amperometric growth of CZTS thin film: Deposition current and stoichiometry relationship, Ceramics International, 47, (2021), 24841-24851.

[3] S.Y. Gwee, S.M. Ho, W.T. Tan, K. Anuar, Influence of $\mathrm{pH}$ values on chemical bath deposited $\mathrm{FeS}_{2}$ thin films, Pacific Journal of Science and Technology, 10, (2009), 801-805.

[4] A.Gervais, D. Malik, D. Linda, A. Ahmed, T. Peter, T. Moyo, Molecular precursor route for the phase selective synthesis of $\alpha-\mathrm{MnS}$ or metastable $\gamma-\mathrm{MnS}$ nanomaterials for magnetic studies and deposition of thin films by AACVD, Materials Science in Semiconductor Processing, 139, (2022). 
Asian Journal of Basic Science \& Research

Volume 4, Issue 1, Pages 01-09, January-March 2022

[5] G. Perna, V. Capozzi, A. Minafra, P. Biagi, Structural and optical properties of pulsed laser-deposited ZnSe films. Applied Surface Science, 186, (2002), 521-526.

[6] X. Wang, C. Yu, J. Wu, Z. Wei, Solvothermal Synthesis of Superhydrophobic ZnS Film, Asian Journal of Chemistry, 25, (2013), 1241-1243.

[7] L. Kun, H. Wang, K. Zhang, L. Wang, Z. Hui, Effect of evaporation rate on the properties of ZnS films, Vacuum, 58, (2021), 15-19.

[8] P. Peng, H. Zhang, L. Song, Y. Jiang, L. Wang, K. He, Molecular Beam Epitaxy Growth and Scanning Tunneling Microscopy Study of Pyrite $\mathrm{CuSe}_{2}$ Films on $\mathrm{SrTiO}_{3}$, Chinese Physics Letters, 32, (2015), https://doi.org/10.1088/0256-307X/32/6/068104.

[9] D. Shin, D.Hwang, Y.Kim, S.Son, S.Guk, J.Park, D.Kim, Effect of RF Power on the Properties of Sputtered-CuS Thin Films for Photovoltaic Applications. Energies, 13, (2020), https://doi.org/10.3390/ en13030688.

[10] N. Saravanan, K. Anuar, S. Atan, S.M. Ho, Chemical bath deposition of ZnSe thin films: SEM and XRD characterization, European Journal of Applied Sciences, 3, (2011), 113-116.

[11] S. Mahdi, S. Husam, A. Hmood, Structure, morphology, and photoresponse characteristics dependence on substrate nature of grown $\pi$-SnS films using chemical bath deposition, Optical Materials, 123, (2022).

[12] J. Haron, K. Anuar, S.Y. Gwee, S.M. Ho, W.T. Tan, Preparation and characterization of PbSe thin films by chemical bath deposition, Jurnal Kimia, 4, (2010), 1-6.

[13] T. Tripurari, L. Jouko, K. Maarit, Atomic Layer Deposition of Conducting CuS Thin Films from Elemental Sulfur. Advanced Materials Interfaces, 5, (2018), https://doi.org/10.1002/admi.201701366.

[14] A.Isac, M. Nanu, A. Kriza, A. Duta, The growth of CuS thin films by Spray Pyrolysis. Journal of physics: Conference Series, 61, (2007), https://doi.org/10.1088/1742-6596/61/1/096.

[15] K. Noraini, K. Anuar, S.M. Ho, N. Saravanan, XRD and AFM studies of ZnS thin films produced by electro deposition method, Arabian Journal of Chemistry, 3, (2010), 243-249.

[16] L. Kadam, N. Ravindra, A. Rupali, Y. Ashik, Electrochemical Synthesis of CuS Thin Film for Supercapacitor Application, Macromolecular Symposia, 392, (2020), https://doi.org/10.1002/masy.201900209.

[17] M. Haron, S.M. Ho, N. Saravanan, K. Anuar, Effect of deposition period and bath temperature on the properties of electrodeposited Cu4SnS4 films. Solid State Science and Technology, 17, (2009), 226-237.

[18] H. Fatima, P. Annie, C. Yuan, M. Record, Deposition of Sb2Se3 thin films on Pt substrate via electro-chemical atomic layer epitaxy (EC-ALE), Journal of Electro analytical Chemistry, 879, (2020).

[19] K. Anuar, K.S. Lim, S.M. Ho, N. Saravanan, SEM, EDAX and UV-visible studies on the properties of Cu2S thin films, Chalcogenide Letters, 8, (2011), 405-410.

[20] G. Lan, D. Yang, W. Chen, C. Wang, Development and application of physical vapor deposited coatings for medical devices: A review. Procedia CIRP, 89, (2020), 250-262. 
Asian Journal of Basic Science \& Research

Volume 4, Issue 1, Pages 01-09, January-March 2022

[21] M. Sara, S. Khuram, S. Shania, Optical and structural properties of single source precursor based pure and $\mathrm{Cu}$-doped antimony sulphide thin films by physical vapour deposition assisted technique, Chemical Physics, 539, (2020), https://doi.org/10.1016/j.chemphys.2020.110979.

[22] N. Saravanan, S.M. Ho, K. Anuar, A. Abdul, K. Noraini, Influence of the deposition time on the structure and morphology of the $\mathrm{ZnS}$ thin films electrodeposited on indium ton oxide substrates, Digest Journal of Nanomaterials and Biostructures, 5, (2010), 975-980.

[23] K. Arun, K. Yadav, S. Tomar, H. Yun, K. Ravi, M. Kumar, Highly responsive and low-cost ultraviolet sensor based on $\mathrm{ZnS} / \mathrm{p}-\mathrm{Si}$ heterojunction grown by chemical bath deposition. Sensors and Actuators A: Physical, 331, (2021), https://doi.org/10.1016/j.sna.2021.112988.

[24] S. Hemdan, M. Rabia, M. Shaban, Controlled synthesis of CdS nanoflowers thin films for H2 electro-generation, Materials Science in Semiconductor Processing, 120, (2020), https://doi.org/10.1016/j.mssp. 2020.105307.

[25] W.T. Tan, S.M. Ho, K. Anuar, H. Abdul, Deposition and characterization of Cu4SnS4 thin films by chemical bath deposition method, Macedonian Journal of Chemistry and Chemical Engineering, 29, (2010), 97-103.

[26] W. Juan, L. Chao, D. Chen, C. Sun, Z. Yang, Interlayered $\mathrm{MoS}_{2} / \mathrm{rGO}$ thin film for efficient lithium storage produced by electrospray deposition and far-infrared reduction, Applied Surface Science, 499, (2020), https://doi.org/10.1016/j.apsusc.2019.143940.

[27] A.Ghazai, Y. Qader, F. Habubi, S. Chiad, Investigation of some physical properties of Mn doped ZnS nano thin films. AIP Conference Proceedings, 2213, (2020), https://doi.org/10.1063/5.0000158.

[28] S. Kannan, P. Subiramaniyam, M. Sathishkumar, Effect of annealing temperature and Mn doping on the structural and optical properties of $\mathrm{ZnS}$ thin films for enhanced photocatalytic degradation under visible light irradiation, Inorganic Chemistry Communications, 119, (2020), https://doi.org/10.1016/j.inoche.2020.108068.

[29] G. Jesus, C. Marta, R. Esther, B. Luis, R. Nalda, A. David, Femtosecond Double-Pulse Laser Ablation and Deposition of Co-Doped ZnS Thin Films, Nanomaterials, 10, (2020), https://doi.org/10.3390/nano10112229.

[30] A.Sabah, A. Kabaa, A. Omar, A. Razak, Influence of CuS powder concentration on the construction of hybrid PVA/CuS thin films for polymer light-emitting applications, Journal of Materials Science: Materials in Electronics, 31, (2020), 3456-3465.

[31] J. Bai, J. Yang, W. Dong, B. Wei, X. Tang, Structural and magnetic properties of perovskite $\mathrm{SrMnO}_{3}$ thin films grown by molecular beam epitaxy, Thin Solid Films, 644, (2017), 57-64.

[32] H. Maryam, M. Seyed, T. Fariba, T. Nima, Aqueous spray pyrolysis of CuInSe $e_{2}$ thin films: Study of different indium salts in precursor solution on physical and electrical properties of sprayed thin films, Materials Science in Semiconductor Processing, 126, (2021), https://doi.org/10.1016/j.mssp.2021.105676.

[33] J. Ben, K. Medjnoun, Z. Ben, K. Djessas, $\mathrm{CuInS}_{2}$ thin films obtained through an innovative CSVT deposition method from solvothermal-generated precursors, Materials Science in Semiconductor Processing, 83, (2018), 224-230. 
Asian Journal of Basic Science \& Research

Volume 4, Issue 1, Pages 01-09, January-March 2022

[34] H. Pathan, D. Lokhande, Deposition of metal chalcogenide thin films by successive ionic layer adsorption and reaction (SILAR) method, Bulletin of Materials Science, 27, (2004), 85-111.

[35] G. Laukaitis, S. Lindroos, M. Rackaitis, M. Leskela, SILAR deposition of CdxZn1-xS thin films, Applied Surface Sciences, 161, (2000), 396-405.

[36] P. Samantha, G. Della, J. Ren, C. Elena, A. Martucci, SILAR Deposition of Metal Oxide Nanostructured Films, Nano Micro Small, 17 (2021), https://doi.org/10.1002/smll.202101666.

[37] S. Sartale, D. Lokhande, Preparation and characterization of nickel sulphide thin films using successive ionic layer adsorption and reaction (SILAR) method, Materials Chemistry and Physics, 72, (2001), 101-104.

[38] S. Hua, J. Mu, SILAR Deposition of CdS Thin Films on Glass Substrates Modified with 3Mercaptopropyltrimethoxysilane, Journal of Dispersion Science and Technology, 26, (2005), https://doi.org/10. 1081/DIS-200063026.

[39] G. Betil, M. Saglam, A. Ates, Effects of SILAR cycle on the electrical characteristics of Cd/CdSe/n-Si/Au-Sb structure, Turkish Journal of Physics, 35,(2011), 1-12.

[40] K. Choy, Chemical Vapour Deposition (CVD): Advances, Technology and Applications, CRC Press, 2019.

[41] K. Wasa, I. Kanno, H. Kotera, Handbook of Sputter Deposition Technology: Fundamentals and Applications for Functional Thin Films, Nano-Materials and MEMS, William Andrew, Amsterdam, 2012.

[42] M. David, Materials, Preparation, and Characterization in Thermoelectrics, CRC Press, Florida, 2017.

[43] M.D. Rowe, Thermoelectrics and its Energy Harvesting, 2-Volume Set, CRC Press, Florida, 2018.

[44] N. Farzad, Electrodeposition of Nanostructured Materials, Springer, Berlin, 2016.

[45] C. Usha, Recent Applications in Sol-Gel Synthesis, BoD-Books on Demand, Norderstedt, 2017.

[46] L. Zhou, T. Nan, S. Wu, X. Hu, Y. Xue, Influence of Deposition Time on ZnS Thin Films Performance with Chemical Bath Deposition, Physics Procedia, 22, (2011), 354-359.

[47] A.Huda, N. Saadah, S. Shaari, Effect of Deposition Time on ZnS Thin Films Properties by Chemical Bath Deposition (CBD) Technique, World Applied Sciences Journal, 19, (2012), 1087-1091.

[48] R. Zein, A. Ibrahim, Influence of Bath Temperature and Deposition Time on Topographical and Optical Properties of Nanoparticles ZnS Thin Films Synthesized by a Chemical Bath Deposition Method, Journal of Nanomaterials, (2019), https://doi.org/10.1155/2019/7541863.

[49] A.Ubale, V. Sangawar, K. Kulkarni, Size dependent optical characteristics of chemically deposited nanostructured ZnS thin films, Bulletin of Materials Science, 30, (2007), 147-151.

[50] M. Ezzat, A. Iman, M. Uonis, Preparation of ZnTe thin films using chemical bath deposition technique, Nanocomposites, 6, (2020), 165-172.

[51] R. Sana, A. Azam, P. Azra, Microstructural and optical properties of CuS nanoparticles prepared by sol-gel route, Perspective in Science, 8, (2016), 632-635. 
[52] P. Hepzi, C. Jeyasankari, N. Dharmalakshmi, Synthesis and Characterization of Fe Doped Copper Sulphide Nanoparticles, The International Journal of Analytical and Experimental Modal Analysis. 12, (2020), 1230-1239. [53] Y. Munikrishna, A. Vedavathi, Structural and Optical Characterization of Chemical Bath Deposited FeS2 Thin Films at Different Temperatures, Journal of Applied Sciences, 12, (2012), 1772-1774.

[54] M. Paca, A. Peter, Synthesis, Optical, and Structural Studies of Iron Sulphide Nanoparticles and Iron Sulphide Hydroxyethyl Cellulose Nanocomposites from Bis-(Dithiocarbamato)Iron(II) Single-Source Precursors, Nanomaterials (Basel), 8, (2018), doi: 10.3390/nano8040187.

[55] N. Egwunyenga, L. Okoli, E. Nwankwo, V. Onuabuchi, Effect of SILAR Cycles on the Thickness, Structural, Optical Properties of Cobalt Selenide Thin Films, International Research Journal of Multidisciplinary Technovation, 3, (2021), 1-9.

[56] N. Ghobadi, F. Hafezi, N. Sirvan, M. Mohsen, M. Habibi, A. Ali, Microstructure and Optical Bandgap of Cobalt Selenide Nanofilms, Semiconductros, 53, (2019), 1751-1758.

[57] G. Muddsar, M. Bhuse, S. Mulla, P. Hankare, Morphological and optoelectronic studies on poly-crystalline leaf-like cobalt selenide thin film synthesized using a chemical bath deposition technique, New Journal of Chemistry, 38, (2014), 255-259.

[58] D. Nina, D. Erika, Z. Anna, Mechanochemically synthesized cobalt monoselenide: structural characterization and optical properties, Applied Physics A, 123, (2017), https://doi.org/10.1007/s00339-017-0785-9.

[59] L. Zhu, A. Lam, M. Teo, D. Susac, A. Campbell, R. Parsons, Structure of sputtered Co-Se thin films prepared for an application in catalysis, Journal of Solid Sate Chemistry, 179, (2006), 3942-3948.

[60] B. Wang, F. Liu, J. Li, Y. Lai, Z. Zhang, Preparation and Characterization of Co-Se Thin Films by Electrodeposition, Journal of Inorganic Materials, 26, (2011), https://doi.org/10.3724/SP.J.1077.2011.00403.

[61] F. Liu, B. Wang, Y. Lai, J. Li, Y. Liu, Z. Zhang, Electrodeposition of Cobalt Selenide Thin Films, Journal of the Electrochemical Society, 157, (2010), https://doi.org/10.1149/1.3468675. 